Vantage: Journal of Thematic Analysis

ISSN: 2582-7391

A Multidisciplinary Publication of Centre for Research,

Maitreyi College, University of Delhi

October 2020, Volume 1, Issue 2

Original Research Article

\title{
Back Inside The Lakshman Rekha: Impact of Covid-19 Lockdown on Middle-Class Working Women In Delhi-NCR
}

\author{
Richa Chilana*, Alfisha Sabri and Palak Purwar \\ Department of English, Maitreyi College, University of Delhi \\ *Correspondence: rchilana@ maitreyi.du.ac.in
}

\begin{abstract}
Space plays a key role in the dynamic process of creating and regulating identities and roles, particularly those of gender. In the binary between public and private, the private (or the domestic space) is often relegated to the margins of discourse. When the world is grappling with a pandemic and confined to private space, there is an even more urgent need to assess the impact on men and women separately, the lack of which conceals the prevalent gender inequality. Drawing on the theoretical tools of space and labour in association with women, this research article focuses on the gendered impact of the pandemic by looking at the predicament of middle-class working women in Delhi-NCR and the possible reinstatement of the 'Lakshman Rekha' in their lives. The project, by focussing on women, engages with the intermeshing of personal and professional spaces, the social and economic impact on middle-class working women, and how the pandemic has laid bare the already flawed system of our society.
\end{abstract}

Keywords: Women, COVID-19, Space, Labour, Economy, Delhi-NCR

\section{INTRODUCTION}

According to the World Bank analysis of 2017, an alarming 19.6 million Indian women dropped out of the labour force between 1993 and 2012. The World Bank report of 2019 says that the Female Labour Force Participation Rate (FLPR) in India has been at a staggering low of $21 \%$, whereas the world average stands at $47.14 \%$ (Andres, et al., 2017).

Even with the increasing GDP of India in the last three decades, female participation in the labour force has continued to decline. The huge number of job losses post- 
demonetisation have been mainly those of women (Women in Labour, 2020), a fact that has failed to draw the attention of either the government or mainstream media. The data available, however, lacks the gender lens and therefore, fails to raise questions about the decreasing participation of women in the labour force. To avoid facing similar consequences in the COVID-19 crisis as well, there is an urgent need to study the economic downturn from a gendered lens.

Lockdown, the primary step taken by the Indian government to tackle the first stage of COVID-19 transmission in the country, aggravated the ongoing economic slowdown in India. In India, $90 \%$ of the female labour force is engaged in the informal sector without any job security, healthcare benefits, and funds. With a wide gender pay-gap of $22.5 \%$, the pay cuts and layoffs have highly affected the financial independence of women and might even result in a subsequent drop off in order to attend to domestic duties only (Monster Salary Index, 2019).

The history of previous health crises like SARS, MERS, Ebola and Cholera outbreaks teach us that women are comparatively more severely hit as opposed to men in similar situations, once again supporting the claim that crises reveal the worst inequalities in the societies by making them more tangible. In the case of COVID-19, biologically, men are more prone to the infection "due to sex-based immunological and gendered differences" (Sili, 2020). However, in the non-immediate aspects of the pandemic, the ones that have altered the "normal" like limited mobility, economic downturn, unemployment and labour participation, both paid and unpaid, women have been affected more severely both at present and in the long-run.

The Lakshman Rekha, or the boundary that Sita was not supposed to overstep (and when she did, the repercussions included the repeated questioning of her "purity") has been seen historically as the boundary that separates the private, "protected" space from the outer world, more so for women. This distinction between the home and the world, the inner and the outer, has been seen as a reflection of the divide between the spiritual and the material, primarily for the bhadra mahila, as argued by Partha Chatterjee (1993). The public realm is often associated with corrupting influences which women need to be guarded from, to ensure their "purity" and "honour". 
When political leaders asked India to draw the Lakshman Rekha outside their houses and not overstep it, the media portrayed it as a celebration of domestic bliss. Here, the Lakshman Rekha not only became the distinction between the inner and the outer space, "the ghar and the bahir" (p. 120) (Chatterjee, 1993), the safe and the dangerous, but also an enabler of normative gender roles. In the duration, we witnessed a global increase in domestic violence which was discussed, albeit cursorily on various platforms, however domestic violence is just one out of the long list of the disturbing wide-ranged effects that being locked inside has had on the lives of women.

The popular perception of home in a capitalist, patriarchal society is that of a safe, nurturing, happy place, probably the best place to be in, in times of crisis. How familial space could also be a "locus of struggle" and a "location where production and redistribution take place" is a question that is often ignored. The relations between family members largely reflect underlying social forces and the unequal division of labour that our present social structure rests upon (p. 368) (Hartmann, 1981). Space plays a key role in the dynamic process of creating and regulating identities and defining the boundaries of gender roles (Massey, 1994). The familial space offers certain roles for women to fit in (Tamalapakula, 2020). In the immediate family, she can either be a mother, daughter, sister, or wife. In the public, professional space however, she can exist as an individual, with an identity that is not limited to these predefined roles, an identity that she attempts to construct herself. With the lockdown imposed, we have witnessed a re-application of these gender roles in terms of individual identity, division of labour, socio-economic interdependence, authority and decision making. In rare, special circumstances in which our study is based, there has been a blurring of boundaries between familial and professional space, thus making the gendered inequalities and their effects overlap and amplify each other.

Initially, where the pandemic was being looked at as the great equaliser, gradually but unapologetically, it has peeled off the badges of supposedly egalitarian societies. The social inequalities, be it based on class, gender, or caste, glared at us through our doors, windows, and television or mobile phone screens while we were sitting locked inside our "protected" spaces. Amidst all this, the gendered effects of the pandemic, however, have been ignored by the government, policy makers and the mainstream media alike.

Vantage: Journal of Thematic Analysis, 2020; 1(2): 82-100 
Malik and Naeem have attempted to calculate and analyse the impact of the pandemic on women's health and livelihoods and to understand the reasons for the increased domestic violence in their study based in Pakistan (2020). While they provide a detailed discussion in the form of facts and figures from various surveys, there is a lack of an attempt to understand the changes in domestic and professional space and their interaction/engagement with each other post COVID-19. Our study of the same will assist us in understanding not only the gendered impact of the pandemic, but also the gendered division of labour, and the circumstances in which it has arisen, in the case of middle-class working women in Delhi-NCR.

The pandemic has had adverse effects on a large section of Indian women, popularly known as 'homemakers' who are engaged in unpaid household chores and care work for their families. However, in this research article we wish to bring forth the predicament of women engaged in paid labour who now, in extraordinary circumstances are confined to domestic space. The research revolves around the lived experiences of middle-class women with respect to change of space, gender roles, professional commitments and sense of self, through which we wish to grapple with the possible reinstatement of the Lakshman Rekha that not only limits these women from financial gains but more importantly forces them into unaccounted for domestic labour.

\section{MATERIALS AND METHODOLOGY}

\subsection{Theoretical Framework}

One of the major reasons for women dropping out of the workforce is the housework that they are expected to do. In the case of most metropolitan cities in India, very meagerly paid care work in the form of house help (mostly women) assists middle-class working women at home and gives them the space to work outside home. With the imposition of the lockdown, and with the house help completely abandoned due to various reasons, housework can be seen as an important space where pre-defined gender roles have been witnessed, applied, and challenged.

For this reason, keeping housework at the centre of our study, we have drawn upon Heidi Hartmann's conceptualization of the domestic, familial space as the locus of struggle and a microcosm where gender roles are not only reflected but also created

Vantage: Journal of Thematic Analysis, 2020; 1(2): 82-100 
(Hartmann, 1981). The article also looks at the various ways of defining home and housework as outlined by Iris Marion Young (2005). Gayle Rubin's attempt to understand the creation and history of this gendered division of labour through psychoanalysis has assisted us in understanding the journey of the patriarchal, capitalist society that our study is based in (1975).

The article revisits the domestic space that women have always been associated with, recognizes the importance and dynamics of the two spaces, and attempts to understand what happens when the personal and professional intersect.

\subsection{Demographic Framework}

To collect information from a diverse spectrum of middle-class working women, Google forms were circulated. In-depth telephonic interviews were conducted with a few respondents, to understand their experiences. The manner in which the division of space into public and private with its preoccupation with domesticity and the honour code materialises is governed by intersection of gender with class, caste, ethnicity, region etc. The varied nature of the lived experiences of lower caste, lower class and rural women, although a pertinent and interesting sphere of enquiry is not the focus of this study.

Our research sample of 45 respondents from Delhi- NCR, comprises 21 married, and 24 unmarried women, their ages ranging from 21 to 54. Three of our respondents are women working in essential services, while the rest are working from home as media professionals, teachers, professors, lawyers, bank executives, self-employed, or have been laid off by their employers.

\section{DISCUSSION AND ANALYSIS}

\subsection{Intermixing of the Personal and the Professional Space}

The space inhabited by an individual plays a seminal role in shaping their sense of self and the perception of others. In a society that is stratified along the lines of caste, class, gender etc. predefined roles are assigned to people. As pointed out by Young, in the cyclic process of building and dwelling, lies the patriarchal relation of man and woman (2005). She says, 
In this acquisitive economy women serve as raw materials, caretakers, and goods themselves to be traded. Her role is to be the home by being at home. Her being home gives him comfort and allows him to open on the expanse of the world to build and create. For her, however, the placement is an imprisonment. (p.128)

Although Young talks at length about the equation of women with home, she argues that the values of home should be democratised, and not rejected. Women alone should not be subjected to what Simone de Beauvoir calls the "Sisyphean" task of maintaining the house and catering to the needs of the rest of the family members, or as suggested by Namita Bhandare", "We need to get men in the kitchen" (Women in Labour, 2020).

With women having earned the rights to go out and work, in patriarchal settings, even today, the idea of a working woman is partially, if not entirely, threatening, to many. The problem that working women still face is the expectation to manage the domestic space and its responsibilities. Moreover, what problematizes the situation further is the emergence of the image of the Indian middle-class superwoman, who excels in both her professional and personal life. Bhavani in her study of the Indian middle-class working woman, through the medium of interviews with three women who left their jobs due to the pressure of both housework and professional work argues that the idea of the Indian superwoman is a myth and that women can't have it all (Arabandi \& Bhavnani, 2016). "Even though I have lots of work but honestly there is no motivation. I work to the best of my potential and deliver results because our economic situation is bad. Otherwise I am so done working like this", said one of our respondents, a 32-year-old marketing professional when asked about her experience working from home.

During the lockdown, there were several factors that intensified the problems of these working women. Firstly, with the absence of house help, who under normal circumstances managed if not all, a major part of the housework, the women of the house are expected to look after the house, by either filling in for the absence of the

\footnotetext{
1 Namita Bhandare is an award-winning freelance journalist who writes on gender and other social issues, with nearly 30 years of experience. She was the first gender editor at Mint, has written for Sunday, India Today, Hindustan Times, Foreign Policy and IndiaSpend, and has edited various books and features in a documentary on sexual violence.
} 
house help, or by micromanaging what had to be done, thus reinstating the idea of the superwoman. Secondly, with the children too at home, in case of women who are also mothers, home-schooling was a responsibility expected to be taken up by the woman. Thirdly, in such a time of crisis, women who lacked job security, had to perform to more than the best of their capabilities, to avoid pay-cuts or being laid off. Lastly, and most importantly, all these have collectively reinstated the idea of the ideal domestic woman, or in a way re-drawn the Lakshman Rekha. As a result, we witnessed the draining effect that these expectations have had on the lives of urban middle-class working women.

In our survey, 12 out of 45 respondents mentioned lack of a professional working environment as a primary challenge that they faced while working from home, while seven of them added that a major inconvenience was caused by the mixing of the personal and professional spaces, with the boundaries between the two being blurred completely. $\mathrm{P}^{2}$, said that before the lockdown, it was clear where the personal ended and the professional began, and vice versa, mentioning especially that the time of her commute served as the separation between the two spaces. In that mobility, she found the mental space to relax and reflect on the activities of her day. With the absence of that, however, she says that the anxiety of one space overlaps that of the other, multiplying them and decreasing her overall productivity. On comparing her experience with her brother, who has also been working from home, she said,

When there were calls, messages from work while I was doing the house chore, I would finish the house chore and then go to the call from work. While for my brother, it was different. Suppose he is washing the utensils and he gets a call in between, he would leave that chore, first answer that call and then maybe return to the chore, and by the time somebody would have already finished it.

Reflecting on the perception of housework by working men and women, she suggested that a woman always structures her schedule to prioritise the housework, the needs

$2 \quad \mathrm{P}$ is a 25-year-old content writer working with a start-up in Delhi. She lives with her family. All respondents have been given alphabets as names to protect their identities 
of the other family members, while a man contributes to the house chores only if/when he has finished his office work and has had enough time to relax. Another respondent, a 35-year-old professor agreed that it is very difficult to focus on work when the family is demanding constant attention. When asked about the challenges faced while working from home, a 25-year-old media professional said that the household chores distracted her and she experienced an enormous lack of personal space while conducting online meetings.

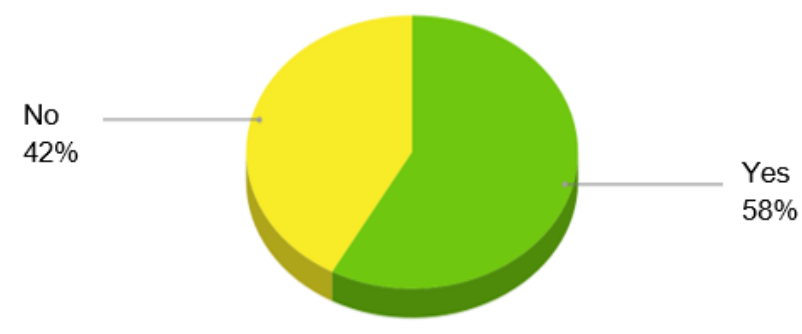

Figure 1: Response of women when asked if the intermixing of the spaces is taking a toll on their health

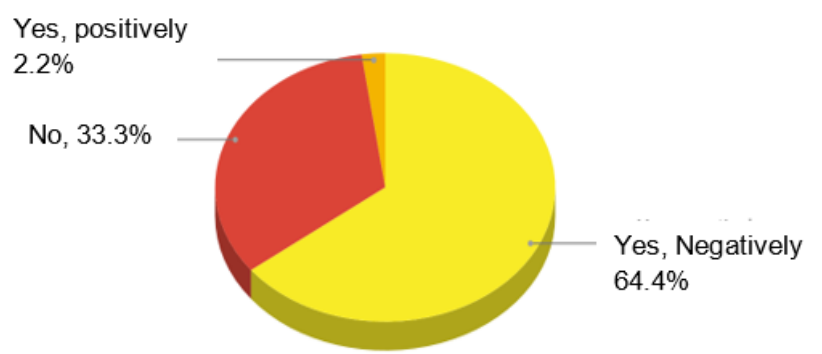

Figure 2: Response of women when asked if they have experienced change in productivity

The effects of this manual drudgery is reflected on the performance of the working woman, both in the professional and domestic space, affecting her physical and mental health. 25 out of the total 45 respondents said that managing both their professional and domestic work had taken a toll on their health (Figure 1). Out of the 45 women, 29 $(64.4 \%)$ said that their productivity had been severely reduced (Figure 2). 87.5\% respondents from the age group of 30-35 reported altered levels of productivity, highest among any other age division. $\mathrm{P}$ told us,

I have realised that ever since the lockdown started, my productivity started going down. Primarily because at home there are more things to distract, more chores to finish, and a comfortable space to work in. But 
most of all, I've been working in extremes, with days in which either I can't get anything done to days in which I'll do 2-3 days of work in a single day, depending on my energy.

Out of all our respondents, only one, who works with an NGO said that her productivity had increased, adding that living with her parents, and with a full-time house help, has given her the upper hand, and helped her make the best out of working from home.

$\mathrm{M}^{3}$ shared that her job that required being in touch with other employees or clients and co-ordinating the work over the phone, left her with very little free time, which she spent waiting for calls. In this duration, her husband expected her to attend to their daughter, who was earlier looked after by a full-time nanny and her in-laws. M, who seems extremely passionate about her work, told us about a little thing that she does when appearing for interviews that require her to relocate to other cities. In the job application form, and the subsequent interview, she does not mention that she is married, or has a child, knowing fully well that these factors will reduce her chances of getting the job. She appears for the interview, gets the job and then refuses to do it, "I was not anyway going to do it, I can't move away from my child", she said. In this way, she added, "I validate myself and tell myself, that it is not me, that lacks, but the factors that surround me." $\mathrm{M}$ also said that she has been to interviews where she was told that she cannot be hired because the company cannot afford the divided focus and priorities that come with a mother,

I am very passionate about my work, I have worked through my pregnancy, I have worked when my child was very young, and I have worked extra hard during the lockdown, to ensure that I wasn't a victim of the salary-cut or lay-off. My family supports me, they know that come whatever may, I will not quit my job. They have never asked me to.

She tells us that her daughter constantly interrupts her when she is attending important work calls. The romanticised concept of motherhood, puts the burden on women to be with their child in its developing years, especially in a country like India where it is

$3 \mathrm{M}$ is a 32-year-old woman working in the marketing sector. She is married, stays in a joint family, and has a 1.5-year-old daughter.

Vantage: Journal of Thematic Analysis, 2020; 1(2): 82-100 
difficult and expensive to find paid childcare services. Even in cases where this is available, a woman who seeks it, is looked down upon as one who is "running away from her responsibilities."

Women are perceived as homemakers or caregivers and conditioned to keep home and family at the top of their priority list, causing serious repercussions in their professional lives. $\mathrm{Q}^{4}$ said that inside the confines of her home, her children see her only as a mother, not as a working woman, and their interruptions during her work makes her teaching process from home less effective. One of our respondents also said that during the course of this lockdown, her daughter has become used to seeing her around a lot, and has developed the habit of clinging on to her. She is worried about what the situation will be like when she has to return to her office.

In academia, a sphere that requires undivided attention and single-minded focus, publications by women academicians have drastically decreased since the beginning of the lockdown (Fazackerly, 2020). Fazackerley recognizes the problem that female academicians specifically have been going through, that is the complete lack of headspace that research requires. She concludes that there is a huge possibility that women will be falling behind in publishing their research "as a result of the hidden labour of domesticity" that universities are yet to recognise. $\mathrm{X}^{5}$ told us that for her, being at home, away from the city, always meant a break and spending time with her family, and resuming her research work at home required great emotional investment and highly affected her ability to produce analytical writing. She added that, "Living in a joint family in the absence of researchers makes it difficult to generate and stabilise interest in my work that requires intense concentration and articulation. Oftentimes, it becomes a downward spiral, since long breaks from research affect its progressive growth." X also told us that she, and many of her colleagues, who left the city for their homes during the lockdown, have been facing a major difficulty in paying the rents of their currently unoccupied apartments in Delhi. She said,

\footnotetext{
4 Q is a 45-year-old teacher, who works in a government school in Delhi NCR. She stays with her husband and two children in Ghaziabad.

$5 \quad \mathrm{X}$ is pursuing her $\mathrm{PhD}$ along with working as a Teaching Assistant in Delhi. With the implementation of the lockdown, she returned home and has been staying with her family since.
} 
This is especially difficult for single women whose jobs are on the line and are staying away from their families in a financially demanding city. There have been a few cases of women being thrown out of their rented houses because they were unable to pay the rent when the lockdown suddenly happened and therefore had to pack their bags to return home. Single women already face much larger consequences of staying in a different city, away from home, and trying to make ends meet.

In a world of virtual learning, many women teachers who were earlier not very well acquainted with technology and online classes, are struggling to fulfill their responsibilities. Q told us that she, like many of her colleagues either didn't own an android phone, or didn't know how to use one. She said, "When the online classes began, we had no idea how things would work with an android phone. I would ask my children for help, but most of the time they were busy. Sometimes they would take the phone saying that they have to do their work."

Our respondents told us that talking about their problems with us has given them a platform for venting out their anxiety, that has been piling up over the months spent juggling between house and work. $\mathrm{P}$ also mentioned that filling the questionnaire for this project made her realise that what she was feeling was not a personal, but rather a universal problem that working women all over the world are currently facing.

From the experiences of our other respondents, we realised that even when women have carved out a niche in their professional spaces, after having battled workplace gender inequality and a very high labour input, paid and unpaid, their association with the domestic space always limits the possibilities of realizing their potential. The established societal structure has created a mindset, which has become even more conspicuous during this pandemic, that expects women to prioritize their domestic responsibilities over their professional careers, the repercussions of which women have to face every day in the form of lost opportunities and subsequently continuously degrading self-worth. 
Earlier, the possibility of going out to work and the household chores being managed by domestic help had camouflaged the divisions and inequalities of domestic space. With the COVID-19 lockdown, restricted mobility has disallowed and discontinued the change of space, making the gender inequality of both these spaces that was earlier ignored, more visible and severe.

\subsection{Women, Labour and COVID-19's Impact}

Women who work outside their homes, are paid, however meagerly, unlike the ones who do the housework and care work at their homes. Rubin argues that the organisation of the sex-gender system done for the purpose of organising the market and the society has developed into a patriarchal system where, because men have the power, women are exploited in terms of labour (1975). Working women, who are paid much less than men, have to do double the work because of the added responsibility of housework, thus degrading their productivity and health.

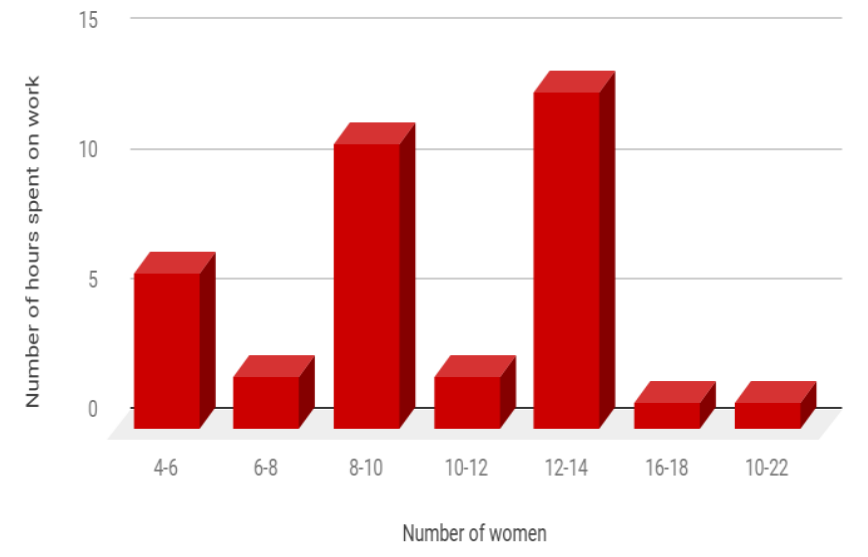

Figure 3: Number of hours spent on work

Adding to this already sad, yet unacknowledged state of women in the labour market are the problems that come with the current shut down and the worsening economic

downturn. For women who are actively participating in the paid labour force, this current shutdown brought with it a twofold workload of 'work from home' and 'work at home' (Sen, 2020). According to an OECD ${ }^{6}$ survey, an average Indian man spends 19 minutes a day on routine day to day housework, while Indian women spend a whopping 298 minutes a day (OECD, 2020). During the lockdown, the average amount of time that women were working (including the paid and unpaid housework but excluding childcare) in a day was 10 hours 18 minutes according to our sample survey.

6 Organisation for Economic Co-operation and Development 
13 respondents reported their working hours to be more than 12 hours a day (Figure 3), while one of them was working for more than 12 hours at her paid job, she was also spending 6 hours doing housework. Repeatedly, this question has been asked, and should be asked, 'What does women's unpaid care work at home account for?' G7 said,

Domestic labour of women (and men) must need accounting for. The pandemic has taught us the value of the underpaid labour of the household workers, too. It is essential to redefine the meaning of work and productivity, especially with regard to women, today.

A 25-year-old professional told us, "Housework has stretched the office hours longer. Also, there is no more clear distinction between home and office. Work and chores. It's just an endless cycle of ticking off one thing after another off a never-ending checklist." When asked if their husbands contributed to the household chores, 7 out of 21 married women said they didn't receive any help, four said that men kept the children engaged while they were working and four others mentioned buying groceries as their husbands' contribution. One woman also mentioned the absence of "unsolicited criticism in the cooked food" as her husband's contribution. "In the school, we are teachers that is what we do, we concentrate on our work. Here, I have to take care of everyone in the family. My husband on the other hand, has only his work to do", Q said. The burden of housework, automatically assigned to women, along with the added responsibility of their professional jobs has drastically increased their net input, making the relentless consequences of the gendered division of labour more visible.

\subsubsection{The Risk of Losing Work}

$\mathrm{P}$, who has undergone a salary-cut tells us that her company, like many others, is either laying off employees or cutting their salary. 17 out of 45 of our respondents said that their professional future is uncertain. $G$ told us, "It is hard to measure the financial/emotional strain the absence of a long-standing job will mean. It will be hard to cope with the struggles of life without stability of work and income." Two women said that although there is no uncertainty regarding their professional future, the pressure to perform well and better than the others has drastically increased. A 23-year-

7 G is a 32-year-old assistant professor working in Delhi. She stays in Gurgaon with her family. 
old woman who has been laid off, told us "I lost my job and I have no savings, I have to take money from my family now." On being asked about the impact of the crisis on her work, T, a 46-year-old single parent, who has been tutoring students for a living for the past 18 years, told us that her only source of income has been taken away from her. She said, "Now, I am not able to finance the higher education of my kids, both above 20, and pay the EMI of my apartment."

$\mathrm{X}$, who makes a contribution to her family's income told us that the uncertainty of her job will affect her family especially now when her father's income has decreased in the past few months. Another respondent, a 25-year old sales professional said, "My manager is laying-off people from the company, I can be one of them. This will definitely affect my family income."

While working from home is already difficult, the demands of the employers are only increasing and becoming more exploitative. P's office hours have increased from nine to twelve, and she receives work even at odd hours. She says, "The manager knows that the employees can't leave the job at this time, because they have no other option. They are taking advantage of this." Moreover, the companies have come up with new policies to maintain the pace of work during and after the lockdown. The threat of being laid off has increased competition among the employees. Women, who have to tend to additional household chores, lag behind in this competition.

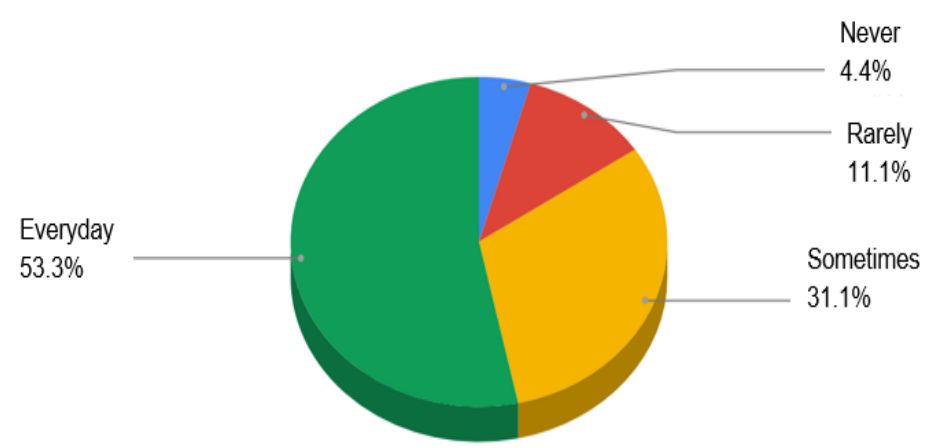

Figure 4: Response when asked about how often they get some free time for themselves

The limited growth of women towards better paying skilled jobs is often because of their domestic duties which leave very little time for their skill enhancement. Out of our 21 married respondents, there was nobody who earned more than their partners. The gender pay gap is real, and so is the gap in the skill development opportunities, the 
former being one consequence of the latter. Out of the 45 respondents, 2 are not able to take out any time from the day for themselves, 5 do it very rarely, 14 do it sometimes, and 24 are able to do it every day (Figure 4). After a long day, with mental and physical fatigue, it is quite challenging to 'learn' something that would propagate individual growth. A 21-year-old media professional told us, "Staying at home, I am either working, or contributing to the house chores, leaving no time for anything else. I get no time to learn something new."

Women engaged in 'feminine' jobs (Young, 2005) such as domestic work, semi-skilled manufacturing sector such as textile, shoe factories, food processing units and hospitality industry have been affected in the worst possible way by the pandemic, although that is a domain of enquiry that is beyond the purview of this report.

To cope with the economic catastrophe of COVID-19, the Indian government announced a twenty lakh crore package, the benefit of which none of our respondents received.

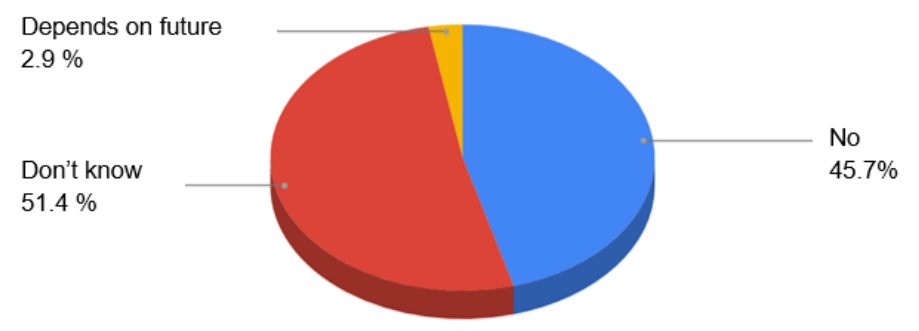

Figure 5: Response to whether the government policies are benefitting the working women

Out of our 45 respondents from the formal sector, 10 said that the government package benefited working women in some ways, 16 said that it didn't, as many as 18 said that they didn't know about the benefits of the package and one woman said that we will know only in the future (Figure 5). The majority of the respondents were not aware of the benefits, showing clearly that lack of awareness, is a major issue that hinders their progress.

A large number of working women are employed on the frontline, accepting the risk of being infected, during this pandemic. Most of them, however, either did not fall into our demographic of middle-class working women, or were difficult to get in touch with. 
Nevertheless, two of our respondents are employed on the frontline, and were working even during the course of the lockdown. One of them, a 24-year old banker, who has been going to the bank regularly, told us that she is partially quarantined and has to stay away from her family to protect them from infection, the possibility of which is making her anxious. She adds that to sanitise her hands time and again after handling the documents or currency notes, takes up a lot of her time. Another respondent, a nurse by profession says that her workload doubled during the lockdown since she had to work increased shifts in the hospital and cater to all the family members at home as well.

\section{CONCLUSION}

The effects of the COVID-19 crisis are certainly going to stay longer than the virus and the brunt of the breakdown of this already flawed system that this crisis has caused, is going to be faced by the marginalised sections of the society, of which women form a large part. Through an analysis of middle-class working in Delhi-NCR, women's familial and professional space and the result of their intermixing post the lockdown, we discussed the impact that this crisis had on their lives. The location of our study in the current COVID-19 pandemic gave us a platform to analyse the gender-based differences at a point where they have become more tangible. In both the spheres, the professional and the familial, their work has overlapped, and increased. This crisis has left women struggling to navigate their way through financial problems, anxiety, increasing competition in the workplace, excessive work, degrading health, and an uncertain future.

Young makes a strong case for the democratisation of home, rather than its abolition, as argued by some other feminists (Young, 2005). Along similar lines, we argue that home is the space that holds the potential to transform and un-form gender roles. Only when the domestic space is democratised, will the professional space echo a similar freedom. Similarly, we need more women in professional spaces so that young girls can identify that space as their own, believe in the possibility of stepping into that space and over the Lakshman Rekha. A woman is often identified as a mother, wife or a daughter in a household setting. The households fail to recognise the same woman as an individual with an identity outside the patriarchal set up inside the domestic space, 
an identity she fashions in the professional space. The COVID-19 induced pandemic which has reinstated the Lashman Rekha has to a great extent also reinstated the conventional/normative identities that working women had attempted to move away from by crossing the threshold, thus women are working at home, from home and for home.

\section{CONFLICT OF INTEREST}

The authors declare that there is no conflict of interest in this research project.

\section{SOURCE OF FUNDING}

Maitreyi College, University of Delhi

\section{ACKNOWLEDGEMENTS}

We are grateful to our Principal, Dr. Haritma Chopra and the Centre for Research, Maitreyi College for providing us a platform and an opportunity to conduct this research. We are also thankful to our college for providing us access to N-LIST, using which we were able to obtain the necessary reading material for this project.

\section{REFERENCES}

Andres, L. A., Dasgupta, B., Joseph, G., Abraham, V., \& Correia , M. (2017). Precarious Drop: Reassessing Patterns of Female Labor Force Participation in India . India: Social Development Unit, South Asia Region.

Arabandi, B. (2016). Karma and the Myth of the Indian Superwoman: Missing Women in the Indian Workforce. In B. Fernandez, M. Gopal , \& O. Ruthven, Land, Labour and Livelihoods: Indian Women's Perspectives. (Ed.) (pp. 177-196) 356 p. Cham: Palgrave Macmillan.

Chatterjee, P. (1993). The Nation and Its Women . In P. Chatterjee The Nation and Its Fragments: Colonial and Post Colonial Histories. (Ed.) (pp. 116-134). 282 p. Princeton : Princeton University Press.

Fazackerly, A. (2020, 12 May). Women's Research Plummets During Lockdown - but Articles from Men Increase. Retrieved from 
https://www.theguardian.com/education/2020/may/12/womens-research-

plummets-during-lockdown-but-articles-from-men-increase

Hartmann, H. I. (1981). The Family as the Locus of Gender, Class, and Political Struggle: The Example of Housework. 366-394. Chicago: The University of Chicago Press

Malik, S., \& Naeem, K. (2020). Impact of COVID-19 Pandemic on Women's Health, Livelihoods and Domestic Violence . Pakistan : Sustainable Development Policy Institute.

Massey, D. (1994). Space, Place, and Gender . 280 p. Minnesota : University of Minnesota Press.

Mittal, A., \& MacGillivray, C. (Co-Producers). (2020, June). Women in Labour [Audio Podcast]. https://www.womeninlabour.com/podcast

Monster Salary Index . India: WageIndicator . (2019, March 7). Retrieved from Outlook India: https://www.outlookindia.com/website/story/business-news-gender-paygap-high-in-india-women-earn-19-per-cent-less-than-menreport/326623\#: :text=According\%20to\%20the\%20latest\%20Monster,stood\% 20at\%20around\%20Rs\%20196.3.

Organization for Economic Cooperation and Development. (2020). Time Spent in Paid and Unpaid Work. Retrieved June 26, 2020, from OECD https://stats.oecd.org/index.aspx?queryid=54757

Raman, A. (2020, July 4). At the forefront of India's healthcare system, ASHA workers soldier on - unprotected and poorly paid. Retrieved July 5, 2020, from The Hindu: https://www.thehindu.com/society/at-the-forefront-of-indiashealthcare-system-asha-workers-soldier-on-unprotected-and-poorlypaid/article31979010.ece

Rubin, G. (1975). The Traffic in Women: Notes on the "Political Economy" of Sex. In Rayna R. Reiter (ed.), Toward an Anthropology of Women.(pp. 157-210). Monthly Review Press. 
Sen, R. (2020, May 16). Implications of COVID on Women [Webinar] . Anveshan.

Sili, L. (2020, April 28). COVID-19 and the Impact on Women. Retrieved from International Growth Centre: https://www.theigc.org/blog/covid-19-and-theimpact-on-women/

Tamalapakula, S. (2020, June 1). Women In 'Lockdown': An Intersectional Feminist Analysis [Webinar] . IQAC, Jesus and Mary College. New Delhi .

Young, I. M. (2005). On Female Body Experience. House and Home: Feminist Variations on a Theme (pp. 123-154). 188 p. Oxford: Oxford University Press.

How to cite this article: Chilana, R., Sabri, A. \& Purwar, P. (2020). Back inside the lakshman rekha: impact of covid-19 lockdown on middle-class working women in Delhi-NCR. Vantage: Journal of Thematic Analysis, 1(2): 82-100.

DOI: https://doi.org/10.52253/vjta.2020.v01i02.06

(C) The Author(s) 2020.

This work is licensed under a Creative Commons Attribution 4.0 International License which permits its use, distribution and reproduction in any medium, provided the original work is cited. 